\title{
Several Cytokines and Protein C Levels with the Apache II Scoring System for Evaluation of Patients with Sepsis
}

\author{
Elif Doyuk Kartal ${ }^{1}$, Emine Karkaç${ }^{1}$, Zafer Gülbaş², Saygın Nayman Alpat ${ }^{1}$, Nurettin Erben ${ }^{1}$, Ertuğrul Çolak ${ }^{3}$ \\ ${ }^{1}$ Department of Infectious Diseases and Clinical Microbiology, Faculty of Medicine, Eskişehir Osmangazi University, Eskişehir, Turkey \\ ${ }^{2}$ Department of Hematology, Faculty of Medicine, Eskişehir Osmangazi University, Eskişehir, Turkey \\ ${ }^{3}$ Department of Biostatistics, Faculty of Medicine, Eskişehir Osmangazi University, Eskişehir, Turkey
}

\section{ABSTRACT}

Objective: We investigated whether determination IL-6, IL-8, IL-1 beta and TNF-alpha at baseline, total protein C (PC) levels at time of admission and 48 hours after initiation could complement the Acute Physiology and Chronic Health Evaluation (APACHE) II scoring system to identify patients with sepsis, severe sepsis or septic shock for clinical outcome.

Material and Methods: The study was carried out prospectively. 60 consecutive patients with sepsis, severe sepsis or septic shock were included. Blood samples were obtained at baseline and 48 hours after initiation. Cytokines and PC levels in plasma were measured with an enzyme-linked immunoabsorbent assay (ELISA). APACHE II score was calculated on admission.

Results: Baseline IL-6 levels and PC levels 48 hours after initiation were predictive of increased mortality ( $p=0.016, p=0.044$ respectively). Baseline IL-6, IL-8 and TNF-alpha baseline levels correlate with the severity of physiologic insult, as determined by the APACHE II score. However, our multiple logistic regression analysis of these did not reveal any predictive value in combination with the APACHE II score.

Conclusion: Determination of baseline IL-6 and PC 48 hours after initiation were of predictive value for prognostic evaluation of septic patients, but did not significantly increase predictive power of the APACHE scoring system to identify patients with sepsis for fatal clinical outcome.

Key Words: Interleukin 6, Interleukin 8, Interleukin 1-beta, Tumor necrosis factor-alpha, Protein C, Sepsis, APACHE II

\section{Introduction}

Sepsis is defined as a systemic inflammatory response to infection associated with the activation of a number of host defense mechanisms including the cytokine network, leukocytes and the hemostatic system (1). Proinflammatory cytokines activate the coagulation cascade via tissue factor, inhibit fibrinolysis, and cause a decrease in AT-III and PC, which are the anticoagulant proteins in plasma. The PC pathway also plays a significant role in inflammatory processes and improves the outcome of patients with sepsis (2).

The current use of severity scores, such as the APACHE II or III scoring systems, use age, medical history and physiological determinants, including body temperature, blood pressure, and serum electrolyte concentrations to quantify the degree of physiologic derangement and to predict outcome $(3,4)$.

The severity of sepsis is related to the intensity of the inflammatory host response. Excessive production of proinflammatory cytokines such as tumor necrosis factor (TNF)-a, interleukin (IL) 1b, IL-6 and IL-8 by immunocompetent cells can induce the systemic inflammatory response syndrome (SIRS) and these cytokines play an important role in the development of acute respiratory syndrome or multiple organ dysfunction syndrome (5-7).
This requires being able to show a correlation between the mediators and severity scores of the disease. Even though many studies associated with prognostic factors in sepsis are available to date, the correlation with severity scores of the disease is not very well known. We investigated whether determination IL-6, IL-8, IL-1beta and TNF-alpha at baseline, total protein $C$ (PC) levels at time of admission and 48 hours after initiation could complement the APACHE II scoring system to identify patients with sepsis, severe sepsis or septic shock for clinical outcome.

\section{Material and Methods}

The prospective study was conducted at the university hospital. The study was approved by the institution's ethics committee.

\section{Patients}

Patients were included if they had clinical evidence of systemic inflammatory response syndrome due to infection and evidence of sustained hypotension or organ hypoperfusion as a result of SIRS. Sepsis and severe sepsis or septic shock were defined according to recent guidelines (8). 
The severity of each patient was evaluated on the basis of the APACHE II scoring system (1).

Sixty patients were included in the study and were followed for 28 days or until death.

Exclusion criteria were age $<18$ years, pregnancy, use of cytokines, use of heparine or thrombolytic therapy, end-stage neoplasm or other diseases, history of transplantation, requiring hemodialysis or peritoneal dialysis, treatment for malignant hematological diseases, and patients not expected to survive 24 hours.

\section{Demographics and Baseline Characteristics}

At inclusion, demographic information regarding the patients (age, gender, underlying diseases such as infection with human immunodeficiency virus (HIV), malignancies or diabetes mellitus, prior treatment with immuncompromising (cytostatic or steroidal) drugs or antibiotics) were recorded. APACHE II scores were calculated. Routine hematologic, chemistry, and coagulation parameters were obtained at study entry and followed throughout. Coagulation assays were performed at study entry and followed daily during the initial five days. Data obtained at this time included platelet count, prothrombin time, partial thromboplastin time and fibrinogen levels. Diagnostic investigations of suspected foci of infection (e.g. cultures of blood and tissue) were done according to the decisions of the attending physician.

\section{Blood Sampling Procedures}

Venous blood samples for the determination of plasma levels of cytokines were obtained at the beginning of the study. In addition, venous blood samples for the determination of plasma levels of total PC were collected in vacutainer tubes containing EDTA at the beginning of the study and 48 hours after initiation. All samples were centrifuged at $3000 \mathrm{rpm}$ for 10 minutes. Serum samples for cytokines levels and plasma samples for PC levels were stored immediately at $-70^{\circ} \mathrm{C}$ until processing.

\section{Cytokines Assays}

Plasma concentrations of IL-6, IL-8, IL- $1 \mathrm{~b}$ and TNF- $\alpha$ were measured with an enzyme-linked immunosorbant assay (ELISA, Research Diagnostic, BioSource International, Inc., immunoassay kit, California) according to manufacturer's conditions. The sensitivities of the assays were $<2 \mathrm{pg} / \mathrm{mL}$ for IL-6, $<5 \mathrm{pg} / \mathrm{mL}$ for IL-8, $1 \mathrm{pg} / \mathrm{mL}$ for IL-1 b, $1.7 \mathrm{pg} / \mathrm{mL}$ for TNF- $\alpha$ respectively. The serum levels of these cytokines are below the detection limit in healthy subjects. Results were related to a dose-response curve obtained with recombinant human IL-6, IL-8, IL-1b and TNF- $\alpha$ and expressed as picograms per milliliter.

\section{PC Antigen Assays}

Total PC antigen levels in the heparinized plasma were measured with a commercially available antigen assay Asserachrom Protein C (Stago Diagnostica, Asniers, France) following the manufacturer's instructions. This sandwich-based ELISA uses rabbit antihuman PC F (ab) 2 fragments as the capture antibody. Dilutions in the ratio of $1 / 50$ of plasma samples were made. The reference range is $70-140 \%$ in a normal adult. The reported range was 14.6-max \%. Values of PC levels above the detection limit of assay ( $\max \%$ ) were calculated logarithmically with respect to their optical densities.

\section{Clinical Outcome}

Patients were observed for clinical outcomes, with 28-day all case mortality as the primary outcome measure. The relationship among PC levels at baseline and after 48 hours, cytokines and APACHE II score to 28 -day all cause mortality, were investigated.

\section{Statistical Analysis}

Values of cytokine levels below the detection limit of assay were replaced by 0 . Values of cytokine levels above the detection limit of assay were calculated logarithmically according to optical density. The distributions of all continuous variables for normal distribution were tested using the KolmogorovSmirnov test. The variables with normal distributions were compared between groups by the Student's t-test. MannWhitney $U$ tests were applied for non-normally distributed variables. For normally distributed variables, mean and standard deviation were used, for non-normally distributed variables median and $25^{\text {th }}-75^{\text {th }}$ percentiles were used. Categorical variables were compared between groups with chi-square analysis. Correlations between variables were determined by using the Pearson correlation analysis for normally distributed variables, and by the Spearman correlation analysis for non-normally distributed variables. Forward multiple logistic regression analysis was used for PC 48 hours after initiation, baseline IL-levels and APACHE II score to predict mortality. The power of the study was calculated as 0.595. This power value was obtained using the SigmaStat 3.5 programme according to the APACHE II score with 60 sample size.

\section{Results}

We prospectively enrolled 60 patients meeting the criteria for sepsis $(n=41)$, severe sepsis or septic shock $(n=19) .24$ patients were female and 36 male, with a mean age of $58 \pm 18.2$ years. Infections were microbiologically proven in 39 of 60 infected patients (65\%). $12 \%$ of septic patients and $58 \%$ of septic shock or severe sepsis had positive blood cultures. In total, 21 patients were deceased. The mean APACHE II score was 17.3. The APACHE II score, mean baseline IL-6 level and PC level at 48 hours after initiation were significanly higher in the severe sepsis or septic shock group than in the sepsis group $(p=0.000, p=0.016$ and $p=0.044$, respectively). The mean baseline IL-1 b, IL-8, TNF- $\alpha$ and PC did not differ between sepsis and severe sepsis or septic shock patients. The main patient characteristics, cytokine levels, PC levels baseline and 48 hours after initiation, APACHE II scores and mortality rates are shown in Table 1.

Cytokine levels did not differ according to the source of infection. Cytokine levels also did not differ with positive blood culture results. Table 2 shows the focus of infection and causative organism and blood culture results.

The APACHE II score, baseline IL-6 level and PC level at 48 hours after initiation were significantly higher in deceased 
Table 1. Demographic data, Cytokine levels, PC levels, APACHE II scores and mortality rates of patients

\begin{tabular}{|c|c|c|c|}
\hline & $\begin{array}{l}\text { Sepsis } \\
(n=41)\end{array}$ & $\begin{array}{l}\text { Severe sepsis } \\
\text { Septic shock } \\
\quad(n=19)\end{array}$ & $\begin{array}{c}p \\
\text { value }\end{array}$ \\
\hline Age & $56.5 \pm 18.2$ & $61.5 \pm 18.4$ & 0.329 \\
\hline Gender (M/F) & $24 / 17$ & $12 / 7$ & 0.955 \\
\hline APACHE II score & $15 \pm 6.9$ & $22 \pm 6.1$ & $0.0^{*}$ \\
\hline Protein C baseline, \% & $106 \pm 43.2$ & $84 \pm 51.6$ & 0.098 \\
\hline PC 48 hours, \% & $67.8 \pm 17.1$ & $56.7 \pm 19.6$ & $0.044^{*}$ \\
\hline $\mathrm{IL}-1 \beta \mathrm{pg} / \mathrm{mL}$ & $23.7 \pm 14.4$ & $25.5 \pm 19$ & 0.696 \\
\hline $\begin{array}{l}\text { Il-6 } \mathrm{pg} / \mathrm{mL} \\
\left(27^{\text {th }}-75^{\text {th }}\right. \\
\text { percentiles })\end{array}$ & $\begin{array}{c}106.4 \\
(49.2-302.3)\end{array}$ & $\begin{array}{c}244.2 \\
(113.5-544.2)\end{array}$ & $0.016^{*}$ \\
\hline $\begin{array}{l}\text { IL-8 } \mathrm{pg} / \mathrm{mL} \\
\left(27^{\text {th }}-75^{\text {th }}\right. \\
\text { percentiles })\end{array}$ & $\begin{array}{c}11.9 \\
(1.8-52.6)\end{array}$ & $\begin{array}{c}9.6 \\
(6.6-67)\end{array}$ & 0.435 \\
\hline $\begin{array}{l}\text { TNF- } \alpha \mathrm{pg} / \mathrm{mL} \\
\left(27^{\text {th }}-75^{\text {th }}\right. \\
\text { percentiles })\end{array}$ & $\begin{array}{c}4 \\
(2-8.6)\end{array}$ & $\begin{array}{c}5.5 \\
(2.9-10)\end{array}$ & 0.393 \\
\hline Mortality (n) & 12 & 9 & 0.282 \\
\hline
\end{tabular}

Table 2. Focus of infection and causative organism in blood cultures

\begin{tabular}{|lcc|}
\hline \multicolumn{1}{|l}{} & $\begin{array}{c}\text { Sepsis } \\
(n=41)\end{array}$ & $\begin{array}{c}\text { Severe sepsis } \\
\text { Septic shock } \\
(n=19)\end{array}$ \\
\hline Focus & 11 & 4 \\
Lung & 12 & 6 \\
Skinary tract & 6 & 5 \\
Abdomen & 5 & 2 \\
Others & 7 & 2 \\
Microbes & & 3 \\
Gram-positive bacteria & 3 & 5 \\
Gram-negative bacteria & 1 & 1 \\
Polybacterial & 0 & 2 \\
Fungi & 1 & 3 \\
\hline
\end{tabular}

than in survivors $(p=0.017, p=0.016$ and $p=0.049$ respectively). Demographic data, cytokine levels, PC levels, and APACHE II scores of both surviving and deceased patients are shown in Table 3.

In the present study, forward multiple logistic regression analysis were used for IL-6 levels, PC levels at baseline, 48 hours after initiation and APACHE II scores to predict mortality. Only the APACHE II score (OR: 1.098, $p=0.022$ ) was found to be an independent predictor for mortality of septic patients. In addi-
Table 3. Demographic data, Cytokine levels, PC levels, APACHE II scores of surviving and deceased patients

\begin{tabular}{|c|c|c|c|}
\hline & $\begin{array}{l}\text { Survived } \\
(n=39)\end{array}$ & $\begin{array}{l}\text { Deceased } \\
\quad(n=21)\end{array}$ & $\begin{array}{c}p \\
\text { value }\end{array}$ \\
\hline Age & $56.2 \pm 20.9$ & $61.6 \pm 11.6$ & 0.204 \\
\hline Gender (M/F) & $24 / 17$ & $12 / 7$ & 0.955 \\
\hline APACHE II score & $15.6 \pm 7.4$ & $20.4 \pm 6.6$ & $0.017^{*}$ \\
\hline PC Baseline, \% & $106 \pm 48.3$ & $85.5 \pm 41$ & 0.095 \\
\hline PC 48 hours, \% & 71.9 & 64 & $0.049 *$ \\
\hline$\left(27^{\text {th }}-75^{\text {th }}\right.$ percentiles $)$ & $(54.6-80.3)$ & $(54-73)$ & \\
\hline $\mathrm{IL}-1 \beta \mathrm{pg} / \mathrm{mL}$ & $23.7 \pm 14.6$ & $25.4 \pm 18.3$ & 0.707 \\
\hline IL-6 pg/mL & 106.7 & 164.4 & $0.016^{*}$ \\
\hline$\left(27^{\text {th }}-75^{\text {th }}\right.$ percentiles) & (57.3-343) & $(81.8-492.3)$ & \\
\hline IL-8 pg/mL & 9 & 18.7 & 0.435 \\
\hline$\left(27^{\text {th }}-75^{\text {th }}\right.$ percentiles) & $(2.3-51.8)$ & $(7-66.2)$ & \\
\hline TNF- $\alpha \mathrm{pg} / \mathrm{mL}$ & 4.8 & 4 & 0.393 \\
\hline$\left(27^{\text {th }}-75^{\text {th }}\right.$ percentiles) & $(2-9.5)$ & $(3-8.9)$ & \\
\hline
\end{tabular}

tion baseline IL-6 and PC levels 48 hours after initiation measurements did not reveal any predictive value of mortality in combination with the APACHE score tested (Figure 1).

The correlation between the APACHE score and blood IL6, IL-8, IL-1beta and TNF-alpha were analyzed. A significant positive correlation was observed between them except IL-1 $b(p=0.002, p=0.007, p=0.851, p=0.018$, and $p=0.326$ respectively) (Table 4). The correlation between the APACHE score and $\mathrm{PC}$ baseline and 48 hours after initiation were also analyzed. No correlation between the APACHE score and PC levels (baseline and 48 hours after initiation) was detected. PC levels baseline and 48 hours after initiation were not associated with cytokines.

Despite the significant positive correlation between IL-6, IL-8, TNF-a and APACHE II scores, our multivariate analysis of these did not reveal any predictive value in combination with the APACHE II score.

\section{Discussion}

The interrelationships between endogenous mediators and their roles in the pathophysiology of systemic inflammation are extremely complex. Multiple mediators have been identified, both other proinflammatory mediators and antiinflammatory mediators $(9,10)$. Proinflammatory cytokines activate the coagulation cascade via tissue factor, inhibit fibrinolysis, and cause a decrease in AT-III and PC, which are the anticoagulant proteins in plasma (11).

Previous studies have shown that there was a similar positive correlation between the APACHE II score and blood IL-6 and TNF- $\alpha$ level on admission to ICU in patients with SIRS and sepsis $(2,12)$. A significant correlation was found among initial serum levels of IL-6, IL-8, TNF- $\alpha$ and the APACHE II score in the present study as in previous studies (12-14). In the study 


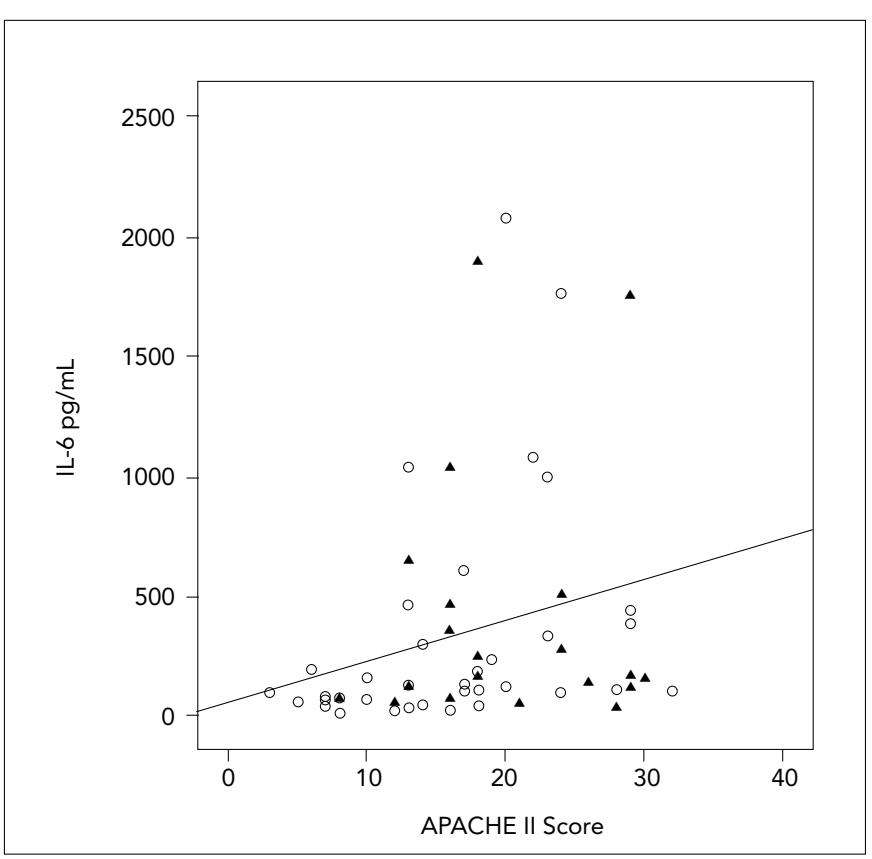

Figure 1. Correlations between baseline APACHE II score and plasma IL-6 concentrations $\triangle$ : Patients that died, $\bigcirc$ : Patients that survived

of Presterl et al., TNF-a was not found to be correlated with any scoring system, while IL-6 was found to be correlated with MPM II and APACHE III score on day 1 and 2 respectively. The authors suggested that IL- 6 should be included in the assessment models of outcome prediction patients with sepsis, either associated with or included in a clinical scoring system $(14,15)$. In addition, Dhainaut et al. reported that the predictive power of APACHE II plus IL-6 was higher with respect to the predictive value of the APACHE II alone (13). Oberholzer and colleagues investigated the relationship of several cytokine and physiological scoring systems for predicting the clinical outcome in patients with severe sepsis. They have demonsrated that, of the cytokines examined, only baseline IL-6 and TNF receptor concentrations (TNF-R1) discriminated among patients who survived or died, and only IL-6 concentrations remained significant when combined with age and the baseline APACHE II and MOD scores (14-16). A significant correlation of initial serum levels of TNF- $\alpha$, IL- 6 and other cytokines and the APACHE II scores in 13 patients with meningoccocal and pneumococcal septic shock was reported (12). Recently Uras and colleagues have reported that for serum CRP and IL-6 levels there was no significant difference between neonatal bacterial sepsis and transient tachypnea of newborn (17). This study suggests that IL-6, IL- 8 and TNF- $\alpha$ baseline levels correlate with the severity of the physiologic insult, as determined by the APACHE II score. However, our multivariate analysis of these did not reveal any predictive value in combination with the APACHE II score.

The normal range of circulating levels of PC has been established by several studies and varies over approximately a two-fold range between the upper and lower limits (70\%-140\%) (18-20). Numerous studies have shown that acquired PC deficiency is prevalent in the majority of septic patients and is as- sociated with increased morbidity and mortality (21-23). In the present study, only PC levels 48 hours after initiation in patients who died were below the lower limit. PC levels 48 hours after initiation were found to be a prognostic marker for a fatal clinical outcome. However, our results showed no correlation between total PC concentrations 48 hours after initiation and APACHE II score. In this study, total PC concentration did not offer any predictive advantage over the APACHE II score alone in septic shock patients, as in the study of Oberholzer and colleagues (14).

In recent years, activation of the cytokine cascade and subsequent coagulation abnormalities has begun to attract close attention as a possible factor responsible for multiple organ dysfunction (24). The effectiveness of recombinant human activated PC against severe sepsis has been demonstrated in a multi-center study (25). These findings suggest that sequential monitoring of blood IL-6 levels allows a precise prediction of activation of the coagulation system induced by cytokine activation and subsequent onset of organ dysfunction, thus enabling anti-coagulant therapy and anti-cytokine therapy to be carried out with optimum timing (5). Our data suggests that there are prognostic values of baseline blood IL-6 levels and PC levels 48 hours after initiation in patients with sepsis, and severe sepsis or septic shock at an early stage. Baseline IL 6 levels and PC levels 48 hours after initiation showed no correlation.

\section{Conclusion}

In this prospective evaluation of several different sepsis indicators in a consecutive series of patients, the APACHE II score proved to be the best indicator of sepsis in newly admitted critically ill patients. Although determination of baseline IL-6 and total PC concentrations at 48 hours after initiation have a prognostic value for the outcome of septic patients, this did not significantly increase the predictive power of the APACHE scoring system to identify patients with sepsis for a fatal clinical outcome. Future studies need to evaluate these approaches in patients with sepsis.

\section{Acknowledgements}

A poster prepared from the small part of the raw data of this manuscript was presented at the Meeting of European Congress of Clinical Microbiology and Infectious Diseases in 2006.

\section{Conflict of Interest}

No conflict of interest was declared by the authors.

\section{References}

1. Members of the American College of Chest Physicians/Society of Critical Care Medicine consensus conference: definitions for sepsis and organ failure and guidelines for the use of innovative therapies in sepsis. Crit Care Med 1992;20:864-74. [CrossRef]

2. Satran R, Almog Y. The coagulopathy of sepsis: pathophysiology and management. IMAJ 2003;5:516-20.

3. Knaus WA, Draper EA Wagner DP, Zimmerman JE. APACHE II: A severity of disease classification system. Crit Care Med 1985;13:818-29. [CrossRef] 
4. Knaus WA, Wagner DP, Draper EA, Zimmerman JE, Bergner M, Bastos PG, et al. The APACHE III prognostic system. Risk prediction of hospital mortality for critically ill hospitalized adults. Chest 1991;100:1619-36. [CrossRef]

5. Oda S, Hiroyuki H, Shiga H, Nakanishi K, Matsuda K, Nakamua M. Sequential measurement of IL-6 blood levels in patients with systemic inflammatory response syndrome (SIRS)/sepsis. Cytokine 2005;29:169-75. [CrossRef]

6. Meduri GU, Headley S, Kohler G, Stentz F, Tolley E, Umberger $R$, et al. Persistant elevation of inflammatory cytokines predicts a poor outcome in ARDS:plasma IL-1 $\beta$ and IL-6 levels are consistent and efficient predictors of outcome over time. Chest 1995;107:1062-73. [CrossRef]

7. Damas P, Canivet JL, Groote DD, Vrindts Y, Albert A, Franchimont $\mathrm{P}$, et al. Sepsis and serum cytokine concentrations. Crit Care Med 1997;25:405-12. [CrossRef]

8. Levy MM, Fink MP, Marshall JC, Abraham E, Angus D, Cook D, et al. $2001 \mathrm{SCCM} / \mathrm{ESICM} / \mathrm{ACCP} / \mathrm{ATS} / \mathrm{SIS}$ International Sepsis Definitions Conference Intensive Care Med 2003;29:530-8.

9. Terregino CA, Lopez BL, Karras DJ, Killian AJ, Arnold GK. Endogenous Mediators in Emergency Department patients with presumed sepsis: are levels associated with progression to severe sepsis and death? Ann Emerg Med 2000;35:26-34. [CrossRef]

10. Bellomo R. The cytokine network in the critically ill. Anesth Intensive Care 1992;20:288-301.

11. Pober JS, Cotran RS. Cytokines and endothelial cell biology. Physiol Rev 1990;70:427-51.

12. Gårdlund $B$, Sjölin J, Nilsson A, Roll M, Wickerts CJ, Wretlind B. Plasma levels of cytokines in primary septic shock in humans: correlation with disease severity. J Infect Dis 1995;172:296-301. [CrossRef]

13. Dhainaut JF, Shorr AF, Macias WL, Kollef MJ, Levi M, Reinhart $K$, et al. Dynamic evolution of coagulopathy in the first day of severe sepsis: Relationship with mortality and organ failure.Crit Care Med 2005;33:341-8. [CrossRef]

14. Oberholzer A, Souza SM, Tschoeke SK, Oberholzer C, Abouhamze A, Pribble JP, et al. Plasma cytokine measurments aug- ment prognostic scores as indicators of outcome in patients with severe sepsis. Shock 2005;23:488-93.

15. Presterl $\mathrm{E}$, Staudinger T, Pettermann $\mathrm{M}$, Lassnigg A, Burgmann $\mathrm{H}_{\text {, }}$ Winkler $\mathrm{S}$, et al. Cytokine profile and correlation to the APACHE III and MPM II scores in patients with sepsis. Am J Respir Crit Care Med 1997;156:825-32.

16. Groenoveld ABJ, Tacx AN, Bossink AWJ, van Mierlo GJ, Hack $C E$. Circulating inflamatory mediators predict shock and mortality in febrile patients with microbial infection. Clin Immunol 2003;106;106-15. [CrossRef]

17. Uras N, Karadag A, Tonbul A, Mete E, Kara S, Karabel M, et al. Serum Interleukin-6 Levels in differential Diagnosis of Sepsis and Transient Tachypnea of Newborn. Trakya Univ Tıp Fak Derg 2010;27:257-60.

18. Philippe J, Offner F, Declerck PJ, Leraux-Roels G, Vogelaers D, Baele $G$, et al. Fibrinolysis and coagulation in patients with infectious disease and sepsis. Thromb Haemost 1991;65:291-5.

19. Lorente JA, Garcia-Frade LJ, Landin L, de Pablo R, Torrado C, Renes $E$, et al. Time course of hemostatic abnormalities in sepsis and its relation to outcome. Chest 1993;103:1536-42. [CrossRef]

20. Carvalho AC, Freeman NJ. How coagulation defects alter outcome in sepsis: survival may depend on reversing procoagulant conditions. J Crit Illness 1994;9:51-75.

21. Fourrier F, Chopin C, Goudemand J, Hendrycx S, Caron C, Rime A, et al. Septic shock, multiple organ failure and disseminated intravascular coagulation: compare patterns of antithrombin III, protein C and protein S deficiencies. Chest 1992;101:816-23. [CrossRef]

22. Fisher CJ, Yan SB. Protein $C$ levels as a prognostic indicator of outcome in sepsis and related diseases. Crit Care Med 2000;28:49-56. [CrossRef]

23. Macias WL, Nelson DR. Severe protein deficiency predicts early death in severe sepsis. Crit Care Med 2004;32:223-8. [CrossRef]

24. Levi $\mathrm{M}$, Ten Cate $\mathrm{H}$, van der Poll $\mathrm{T}$. Endothelium: interface between coagulation and inflammation. Crit Care Med 2002;30:S230-4. [CrossRef]

25. Bernard GR, Vincent JL, Laterre PF, LaRosa SP, Dhainaut JF, Lopezodriquez $A$, et al. Efficacy and safety of recombinant human activated protein C for severe sepsis. N Eng J Med 2001;344:699-709. [CrossRef] 